\title{
Sanguinarine triggers intrinsic apoptosis to suppress colorectal cancer growth through disassociation between STRAP and MELK
}

\author{
Xianling Gong ${ }^{1,2+}$, Zhihong Chen ${ }^{2 \dagger}$, Qinrui Han ${ }^{1 \dagger}$, Chunhui Chen ${ }^{1}$, Linlin Jing ${ }^{3}$, Yawei Liu ${ }^{4}$, Liang Zhao ${ }^{4}$,
} Xueqing $\mathrm{YaO}^{5^{*}}$ and Xuegang Sun ${ }^{1,3^{*}}$

\begin{abstract}
Background: Previous studies showed sanguinarine induced apoptosis in CRC cells but did not define the underlying mechanisms. The purpose of this work was to determine the in vivo and in vitro effects of sanguinarine on CRC tumors and to elucidate the mechanism in regulating the intrinsic apoptosis.

Methods: Cell viability of CRC cell lines treated with sanguinarine was measured by MTT assay. Apoptotic cells stained with Annexin $V$ and 7-AAD were detected by flow cytometry. Mitochondrial membrane potential and reactive oxygen species (ROS) were analyzed by JC-1 and DCFH-DA staining, respectively. The in vitro kinase activity of MELK was analyzed by using HTRF KinEASE ${ }^{\text {TM}}$-STK kit. The expression of proteins were determined using Western blotting and immunohistochemistry. Co-immunoprecipitation and immunofluorecence were used to study the interaction between STRAP and MELK. The anti-neoplastic effect of sanguinarine was observed in vivo in an orthotopic CRC model.
\end{abstract}

Results: Sanguinarine decreased the tumor size in a dose-dependent manner in orthotopical colorectal carcinomas through intrinsic apoptosis pathway in BALB/c-nu mice. It significantly increased cleavage of caspase 3 and PARP in implanted colorectal tissues. Sanguinarine increased mitochondrial ROS and triggered mitochondrial outer membrane permeabilization in multiple colorectal cancer (CRC) cell lines. NAC pretreatment lowered ROS level and downregulated apoptosis induced by sanguinarine. The intrinsic apoptosis induced by sanguinarine was Bax-dependent. The elevated expression and association between serine-threonine kinase receptor-associated protein (STRAP) and maternal embryonic leucine zipper kinase (MELK) were observed in Bax positive cells but not in Bax negative cells. Sanguinarine dephosphorylated STRAP and MELK and disrupted the association between them in HCT116 and SW480 cells. The expression and association between STRAP and MELK were also attenuated by sanguinarine in the tumor tissues. Importantly, we found that STRAP and MELK were overexpressed and highly phosphorylated in colorectal adenocarcinomas and their expression were significantly correlated with tumor stages. Furthermore, the expression of MELK, but not STRAP, was associated with lymph node metastasis.

Conclusions: Sanguinarine dephosphorelates STRAP and MELK and disassociates the interaction between them to trigger intrinsic apoptosis. Overexpression of STRAP and MELK may be markers of CRC and their disassociation may be a determinant of therapeutic efficacy.

Keywords: Colorectal cancer, Sanguinarine, MELK, STRAP, Intrinsic apoptosis, Bax

\footnotetext{
* Correspondence: yjb9211@21cn.com; sxg_smu@126.com

${ }^{+}$Xianling Gong, Zhihong Chen and Qinrui Han contributed equally to this work.

${ }^{5}$ Department of Gastrointestinal Surgery, Guangdong General Hospital,

Guangzhou (510120), China

${ }^{1}$ The key laboratory of molecular biology, State Administration of Traditional Chinese Medicine, School of Traditional Chinese Medicine, Southern Medical University, Guangdong, Guangzhou (510515), China

Full list of author information is available at the end of the article
}

(c) The Author(s). 2018 Open Access This article is distributed under the terms of the Creative Commons Attribution 4.0 International License (http://creativecommons.org/licenses/by/4.0/), which permits unrestricted use, distribution, and reproduction in any medium, provided you give appropriate credit to the original author(s) and the source, provide a link to the Creative Commons license, and indicate if changes were made. The Creative Commons Public Domain Dedication waiver (http://creativecommons.org/publicdomain/zero/1.0/) applies to the data made available in this article, unless otherwise stated. 


\section{Background}

Colorectal cancer (CRC) is the third most common cancers expected to occur and the third most common cause of cancer deaths both in men and women in the United States in 2017 [1]. Even multiple modules of treatment including surgical resection and systemic infusional chemotherapy have been applied, the overall 5 year death rate for CRC patients is still about 34\% [2].

Apoptosis includes two main pathways which are termed "extrinsic pathway" and "intrinsic pathway" that involve cell surface death receptors or the mitochondria respectively [3]. The pro-apoptotic proteins Bax or Bak of Bcl-2 family constitute the central effector of the intrinsic pathway [4]. Mitochondria have key roles in intrinsic apoptosis execution. Mitochondrial reactive oxygen species (ROS) signaling increases longevity through the intrinsic apoptosis pathway in the nematode C. elegans [5]. Chemotherapy promotes survival in CRC patients through ROS mediated apoptosis [6, 7]. Bax is a key regulatory role in inducing the mitochondrial outer membrane permeabilization (MOMP) [8]. Mitochondria, the convergence of pro-apoptotic proteins and redox, orchestrate the sequential events of MOMP and intrinsic apoptosis.

Serine-threonine kinase receptor-associated protein (STRAP) is a TGF- $\beta$ receptor-interacting protein that participates in the regulation of cell proliferation and cell death [9]. Maternal embryonic leucine zipper kinase (MELK) is a member of the AMP-activated protein kinase-related kinase family and controls a variety of biological processes, including cell cycle, cell proliferation, carcinogenesis, and apoptosis [10]. STRAP is a positive regulators of MELK and MELK phosphorylates STRAP at Ser188 via direct interaction [9]. Althrough STRAP [11, 12] and MELK [10, 13-15] are highly expressed in multiple human cancers, their association in tumor progression and as a therapeutic target is largely unknown.

Macleaya cordata is a kind of commonly used traditional medicinal plants that first described in Ben Cao Shi Yi ("Supplement to the Materia Medica") in Tang dynasty [16]. Sanguinarine is a major bio-active component that belongs to benzylisoquinoline alkaloid from Macleaya cordata. It has been demonstrated that sanguinarine could induce apoptosis in head and neck cancer cells [17], human colorectal cancer [18] and drug-resistant non-small-cell lung cancer cells [19]. Sanguinarine increased the generation of reactive oxygen species (ROS) and activation of c-Jun-N-terminal kinase (JNK) and nuclear factor-kappa B (NF-kappa B) [17]. We suppose that sanguinarine dictates the apoptosisrelated collapse of the mitochondrial membrane potential to suppress the growth of CRC [20]. The role of STRAP and MELK in regulating MOMP induced by sanguinarine would be documented in our research.

\section{Methods}

Regeants

Antibodies against Caspase-3 (No. 9662), PARP (No. 9532), Pro-caspase 9 (No. 9508), Cleaved Caspase-9 (No. 7237), Cytochrome C (No. 4272), Bcl-2 (No. 2870), Bax (No. 5023) and PCNA (No. 13110) were from Cell Signaling Technology (CST), USA. Anti-maternal embryonic leucine zipper kinase (MELK) (No. ab155767) was obtained from Abcam, UK. Anti-serine-threonine kinase receptor-associated protein (STRAP) (No. sc-377,345) and Caspase 8 (No. sc-56,070) antibody was purchased from Santa Cruz Biotechnology, USA. Anti-phosphoMELK (Thr167, Ser171) (No. WG-00203P) and Antiphospho- STRAP (Thr175, Ser179) (No. WG-00204P) were ordered from ABclonal Technology, China. Alexa fluor 488 goat anti-rabbit $\operatorname{IgG}(\mathrm{H}+\mathrm{L})$ (No. CA11008s) and Alexa fluor 546 goat anti-mouse $\operatorname{IgG}(\mathrm{H}+\mathrm{L})$ (No. A11003) were obtained from Molecular Probes (Invitrogen). Beta-actin antibody (No. E021020-01) was from EarthOx, LLC, San Francisco, USA. Sanguinarine was purchased from National Institutes of Food and Drug Control (Beijing, China). Sanguinarine was dissolved in DMSO (MP, France) and diluted in culture medium for each experiment. The final concentration of DMSO didn't exceed $0.1 \%$.

\section{Cell lines and cell culture}

Human colon carcinoma cell lines SW480 (cat. No. TCHu172) and HCT116 (WT) (cat. No. TCHu 99) were purchased in 2014 from the Chinese Academy of Science Committee Type Culture Collection Cell Bank (Shanghai, China). HCT116 $\mathrm{Bax}^{-/-}$human colon carcinoma cell line was a generous gift from Dr. Bert Vogelstein (Howard Hughes Medical Institute, MD). SW480 and HCT116 (WT) cells were cultured in RPMI 1640 medium (Gibco) and HCT116 $\mathrm{Bax}^{-/-}$cells in McCoy's 5A medium (Invitrogen). The medium was supplemented with $10 \%$ fetal bovine serum (Gibco) and 1\% penicillin-streptomycin (Invitrogen). All cells were maintained at $37{ }^{\circ} \mathrm{C}$ in a humidified incubator of $5 \% \mathrm{CO}_{2}$-containing atmosphere.

\section{Cell viability assay}

Cells were seeded in 96 wells plates at density of $0.8 \times 10^{4}$ cells per well. Sanguinarine was dissolved in DMSO as a stock solution and was stored in aliquots at $-20^{\circ} \mathrm{C}$. After treatment with or without sanguinarine, MTT (3-[4, 5dimethylthiazolyl-2]-2, 5-diphenyl tetrazolium bromide) (MP, France) was added into each well. Cells were incubated for $4 \mathrm{~h}$. The formazan crystals were dissolved in DMSO. The absorbance value was measured at $490 \mathrm{~nm}$.

\section{Hoechst 33,342 staining}

Hoechst 33,342 (MP, France) staining was performed according to the manufacturer's instructions. Morphological 
changes in nuclei were observed under a fluorescence microscope using a blue filter (NIKON ECLIPSE Ti-S).

\section{PE-Annexin V/7-AAD staining assay}

Cells were stained with PE-Annexin V/7-AAD (BD Bioscience pharmingen) according to the manufacturer's instructions. Cells were resuspended in $500 \mu \mathrm{L} 1 \mathrm{x}$ binding buffer, $5 \mu \mathrm{l}$ PE-Annexin V and $5 \mu \mathrm{l}$ 7-AAD were added to the sample and incubated at room temperature for $15 \mathrm{~min}$ in the dark. The stained samples were then detected by flow cytometry (BD FACSCalibur).

\section{Western blotting}

Total cells were lysed in RIPA buffer. Mitochondrial and cytoplasmic fractions were isolated according to the manufacturer's instructions of Cell Mitochondria Isolation Kit (Beyotime, China). Mitochondria were lysed in RIPA buffer. The protein concentrations of the mitochondria, cytoplasm and whole cells were determined by the BCA (Thermo scientific) method using the Thermo protein assay kit. Equal amount of proteins from each group were subjected to SDS-PAGE on $12 \%$ gel, transferred to a PVDF membrane (Millipore) by electroblotting, blocked with $5 \%$ nonfat milk for $1 \mathrm{~h}$ at room temperature and incubated with primary antibodies overnight at $4{ }^{\circ} \mathrm{C}$. Next, the membrane was incubated by HRP-conjugated appropriate secondary antibodies, visualized by enhanced chemiluminescence (Millipore) and exposed by KODAK Image Station 4000MM Digital Imaging System [21, 22].

\section{JC-1 staining method}

Cells were stained with JC-1 according to the manufacturer's instructions of Mitochondrial membrane potential assay kit (Beyotime, China). Cells were then detected using flow cytometry (BD FACSCalibur). The mitochondrial membrane potential was calculated based on the following equation: mitochondrial membrane potential $=$ red fluorescence intensity / green fluorescence intensity.

\section{Detection of ROS generation}

After treatment with sanguinarine of different concentration for indicated time, cells were stained with 5-(and 6)carboxy-2', $7^{\prime}$-dichlorodihydrofluorescein diacetate (DCFHDA) according to the manufacturer's instructions of Reactive Oxygen Species Assay Kit (Beyotime, China). Intracellular production of ROS was evaluated by flow cytometry. Relative Ros levels = DCH fluorescence intensity(treatment group) / DCH fluorescence intensity (control group).

\section{QRT-PCR}

Total RNA was extracted with TRIzol (Takara, Dalian, China). $2 \mu \mathrm{g}$ of the total RNA was reversely transcribed using a reverse transcription kit (Takara) according to the manufacturer's protocols and cDNA was obtained. The primers for STRAP were 5'AAGGGACACTTTG GTCCTATTC-3' (fwd), 5'-CCTACCACAGTTTGCCA TAGT-3' (rev). The primers for MELK were 5'- AC TTGCCTGCCATATCCTTAC-3' (fwd), 5'-GGTTCT TCAAGGCCTCAATCT -3' (rev).The primers for GAPDH were 5'-ATTGTCAGCAATGCATCCTG-3' (fwd), and 5'-ATGGACTGTGGTCATGAGCC-3' (rev). All reactions were performed in triplicate for 40 cycles in a Stratagene Mx3005P system as previously described [23]. Relative expression was calculated with GAPDH using the $2^{-\Delta \Delta C t}$.

\section{Immunoprecipitation}

Immunoprecipitation was performed as previously described [24]. Briefly, cell extract was mixed with antiSTRAP, anti-MELK antibody at $4{ }^{\circ} \mathrm{C}$ overnight. Agarose beads were added at a ratio of $1 \mathrm{mg}$ of extract per $120 \mu \mathrm{l}$ of agarose at $4{ }^{\circ} \mathrm{C}$ for $3 \mathrm{~h}$. The beads were then pelleted at $2500 \times \mathrm{g}$ for $3 \mathrm{~min}$ and washed with lysis buffer five times. The beads were subjected to elution with $5 \mathrm{vol}$ of $0.5 \mathrm{mg} / \mathrm{ml}$ peptide for $4 \mathrm{~h}$ or directly boiled in loading buffer.

\section{Immunofluorescence}

Cells were fixing with $4 \%$ paraformaldehyde at room temperature for $25 \mathrm{~min}$ and permeabilized using $0.2 \%$ Triton-100X and then blocked by 5\% BSA at room temperature for $1 \mathrm{~h}$. Next, they were incubated with primary antibody overnight at $4{ }^{\circ} \mathrm{C}$ according to the manufacturer's instructions. Then, the cells were followed by staining with secondary antibodies (Alexa Fluor 488 and 546, Invitrogen). Cell nuclei were stained with DAPI at $37{ }^{\circ} \mathrm{C}$ in darkness for $8 \mathrm{~min}$. Pictures were taken under confocal microscope $\left(\mathrm{NIKON} \mathrm{C2}{ }^{+}\right)$.

\section{Kinase activity assay}

The in vitro kinase activity of MELK was analyzed by using $\mathrm{HTRF}^{\circ}$ KinEASE ${ }^{\mathrm{m}}$-STK kit. It is a generic method for measuring Serine/Treonine kinase activities. The assay was performed according to manufacturer's protocol. MELK Kinase was incubated with sanguinarine and the STK Substrate-biotin for $50 \mathrm{~min}$ at room temperature in the presence of ultrapure ATP. STK Antibody labeled with Eu3 $^{+}$-Cryptate STK Substrate-biotin and streptavidinXL665 were added to the mixture in a single addition with EDTA. They were incubated for $60 \mathrm{~min}$ at room temperature to stop the kinase activity. The kinase activity of MELK were detected by Tecan Infinite 200 PRO microplate spectrophotometer. 


\section{Orthotopic CRC model}

6 to 8 week-old BALB/c-nu male nude mice (NO. 44002100007706) were purchased from Experimental Animal Centre of Southern Medical University. The mice were housed in a specific pathogen-free facility and maintained under $12 \mathrm{~h}$ light/dark cycles. All animal studies were performed according to protocols of the Care and Use of Laboratory Animals published by the National Institutes of Health and approved by the Laboratory Animals Care and Use Committee of Southern Medical University. Orthotopic CRC model on nude mice was established according to our previously described methods [24]. Twenty-Four tumor-bearing male nude mice were randomly divided into four groups $(n=6$ each group) treated with (1) Control diluents; (2) sanguinarine $4 \mathrm{mg} / \mathrm{kg} / \mathrm{d}$ by administeration via oral gavage; (3) sanguinarine $8 \mathrm{mg} / \mathrm{kg} / \mathrm{d}$ by administeration via oral gavage; (4) cisplatin $1 \mathrm{mg} / \mathrm{kg} / \mathrm{d}$ by intraperitoneal injection for 21 days. Nude mice were weighted every 5 days. The mice were anesthetized with Sodium Pentobarbital $100 \mathrm{mg} / \mathrm{kg}$ and then sacrificed at the end of the experiment according to the euthanasia guidelines for experimental animals of Southern Medical University. The tumor tissues were dissected and fixed in $4 \%$ paraformaldehyde for histologic examination or stored at $-80^{\circ} \mathrm{C}$ for western blotting.

\section{Tumor tissue samples}

The collections of tumor and adjacent tissue samples were approved by the Ethics Committee of Guangdong General Hospital and all aspects of the study comply with the Declaration of Helsinki. Informed consents were signed voluntarily by all patients that included in this study. Fresh primary CRC specimens and paired noncancerous colorectal tissue were provided by the Tumor Tissue Bank of Guangdong General Hospital. In each case, a diagnosis of primary CRC had been made, and the patient had undergone elective surgery for CRC in Guangdong General Hospital between 2015 and 2016. The pathological diagnosis was made in the Department of Pathology of Guangdong General Hospital.

\section{Immunohistochemistry}

Tumour tissues from control and treated mice were obtained after sacrificing the mice and then fixed in $4 \%$ paraformaldehyde and embedded in paraffin. Sections were deparaffinized, rehydrated. Endogenous peroxidase activity was blocked with $3 \%(\mathrm{v} / \mathrm{v})$ hydrogen peroxide solution. Heat-induced antigen retrieval was performed. Sections were incubated with 5\% BSA to block nospecific staining. After incubation with the primary antibodies (anti-MELK, anti-STRAP, anti-Bax) overnight at $4{ }^{\circ} \mathrm{C}$ in a humid chamber, sections were incubated with mouse/rabbit-labelled polymer from GTVision ${ }^{\text {TM }}$ III kit (Gene Tech, China) for $1 \mathrm{~h}$ at $37^{\circ} \mathrm{C}$. Positive signals were visualized by DAB kit. The slides were reviewed by two or three pathologists blind to the study. To evaluate the expression levels, immunostained slides were evaluated using a method described previously [25]. TUNEL assay was performed according to manufacturer's protocol of In Situ Cell Death Detction Kit, TMR red (Roche, Mannhem, Germany).

\section{Statistical analysis}

Parallel experiments were repeated three times. Data was analyzed using SPSS 22.0 statistical software. And results are expressed as: mean \pm standard deviation (SD). Mean was compared between groups using one WayANOVA. When the variance was homogeneous, $L S D$ was used for multiple comparisons. Dunnett T3 method was applied for the unequal variances. Mean of two groups was compared with independent samples $\mathrm{t}$ test. A value of $p<0.05$ indicated statistically significant difference.

\section{Results \\ Sanguinarine inhibits the growth of orthotopical implanted CRC by inducing apoptosis}

An orthotopically implanted CRC model was used to characterize the anti-tumoral effects of sanguinarine in vivo [24]. The tumor weight was significantly reduced by both sanguinanine and Cisplatin in situ significantly (Fig. 1b and c). However, the body weight loss caused by sanguinarine was lower than that of caused by cisplatin (Fig. 1a). Increased TUNEL positive cells indicate that the cell death induced by sanguinarine can be defined as apoptosis (Fig. 1d and e). Western blot analysis showed that cleaved PARP and caspase 3 were increased significantly in sanguinarine-treated tissues (Fig. 1f). Further evidence indicated that cell proliferation was dampened by sanguinarine treatment (Fig. $1 \mathrm{~g}$ and $\mathrm{h}$ ). These results suggested that the growth of orthotopical implanted CRC was suppressed by sanguinarine via the induction of apoptosis.

Sanguinarine induces intrinsic apoptosis in CRC cell lines Sanguinarine decreased the cell viability in dose- and time- dependent manner both in SW480 and HCT116 colorectal adenocarcinoma cells as monitored by 3-[4,5dimethylthiazolyl-2]-2,5-diphenyl tetrazolium bromide staining at $24 \mathrm{~h}$ and $48 \mathrm{~h}$ (Fig. 2a). The number of Hoechst positive cells increased simultaneously upon treatment of sanguinanine (Fig. 2b). Chromatin condensation, rounding-up of the cells, cell shrinkage and extensive detachment of the cells from the cell culture substratum were observed by Hoechst 33,342 staining (Additional file 1: Figure S1 and Additional file 2: Figure S2). Flow cytometry showed that annexin V positive cells were significantly increased by sanguinarine treatment at 
a

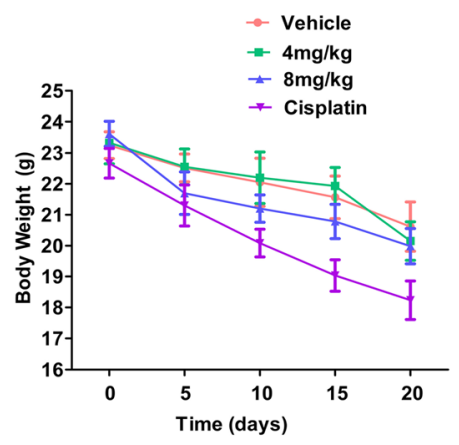

C

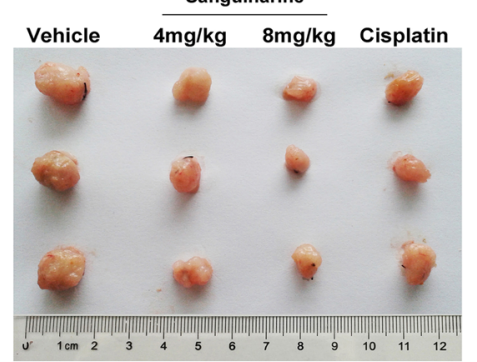

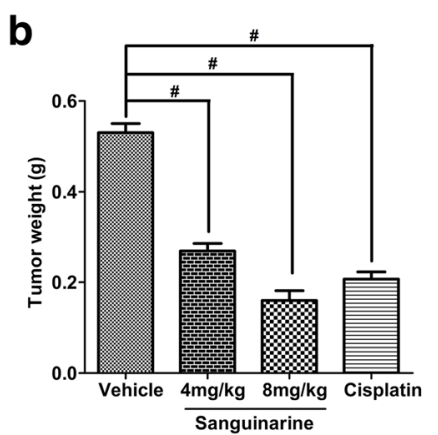

e

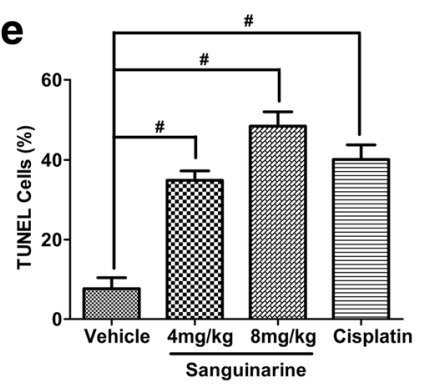

d
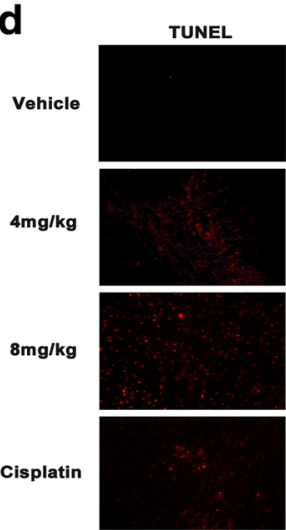

g
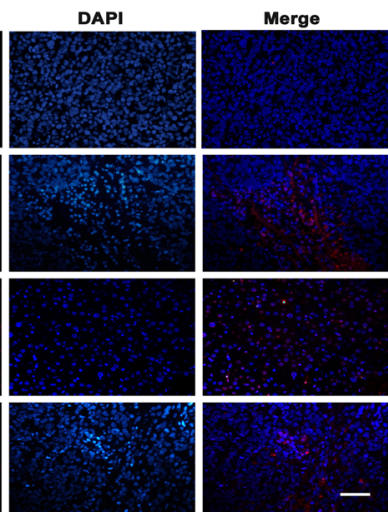

$4 \mathrm{mg} / \mathrm{kg}$

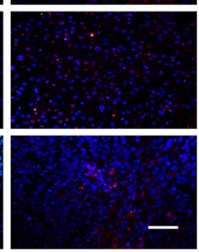

$8 \mathrm{mg} / \mathrm{kg}$

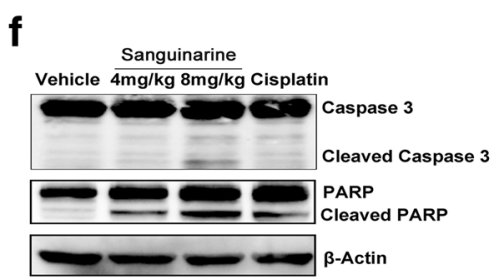

h

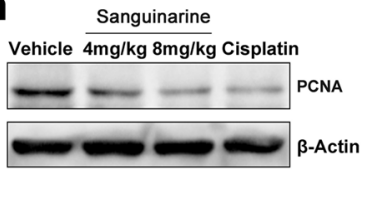

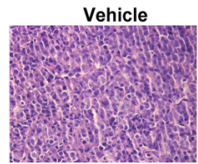
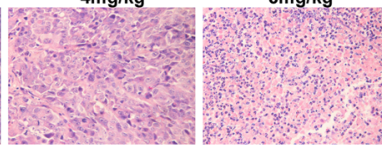

Cisplatin

Fig. 1 Sanguinarine inhibited the growth of orthotopic CRC in nude mice by inducing apoptosis. a Effect of sanguinarine and Cisplatin on body weight of nude mice bearing xenografts. b Photographs of tumors were from four groups. c Tumor weight of mice from Orthotopic implanted CRC model. $\mathbf{d}$ Tumors were dissected and tested using TUNEL staining kit (red) and DAPI (blue). The slides were observed by inverted fluorescence microscope (400x) (Scale bar is 50 mm). e Apoptosis was analyzed quantitatively by calculating percentage of the number of cells with TUNEL staining as compared to the total number of cells. $\mathbf{f}$ The apoptosis corresponding proteins from tumor tissue were analyzed by western blotting. g Representative photographs of H\&E staining (400X) (Scale bar is $50 \mu \mathrm{m})$. $\mathbf{h}$ PCNA protein from tumor tissue was detected by western blotting. Data presented are showed as means \pm SD from three independent experiments. ${ }^{\#} p<0.01$ indicates significant difference

$24 \mathrm{~h}$ and $48 \mathrm{~h}$ in a dose-dependent manner (Fig. 2c). Analysis of flow cytometry were presented in Additional file 3: Figure S3. To further define the cell death subroutines, cells were preincubated with a pan-caspase inhibitor, $\mathrm{N}$ benzyloxycarbonyl-Val-Ala- Asp(OMe)-fluoromethyl ketone (Z-VAD-FMK). The annexin $\mathrm{V}$ positive cells were significantly reduced and the viability were elevated correspondingly by Z-VAD-FMK pretreatment (Fig. 2d and
Additional file 4: Figure S4). These results suggested that sanguinarine induced apoptosis is the main cause for the reduced cell viability.

\section{Sanguinarine increase ROS to induce MOMP}

Apoptosis is a highly coordinated process that orchestrates a series of biochemical events. It recruits the proapoptotic members of the Bcl-2 family, such as Bax or 

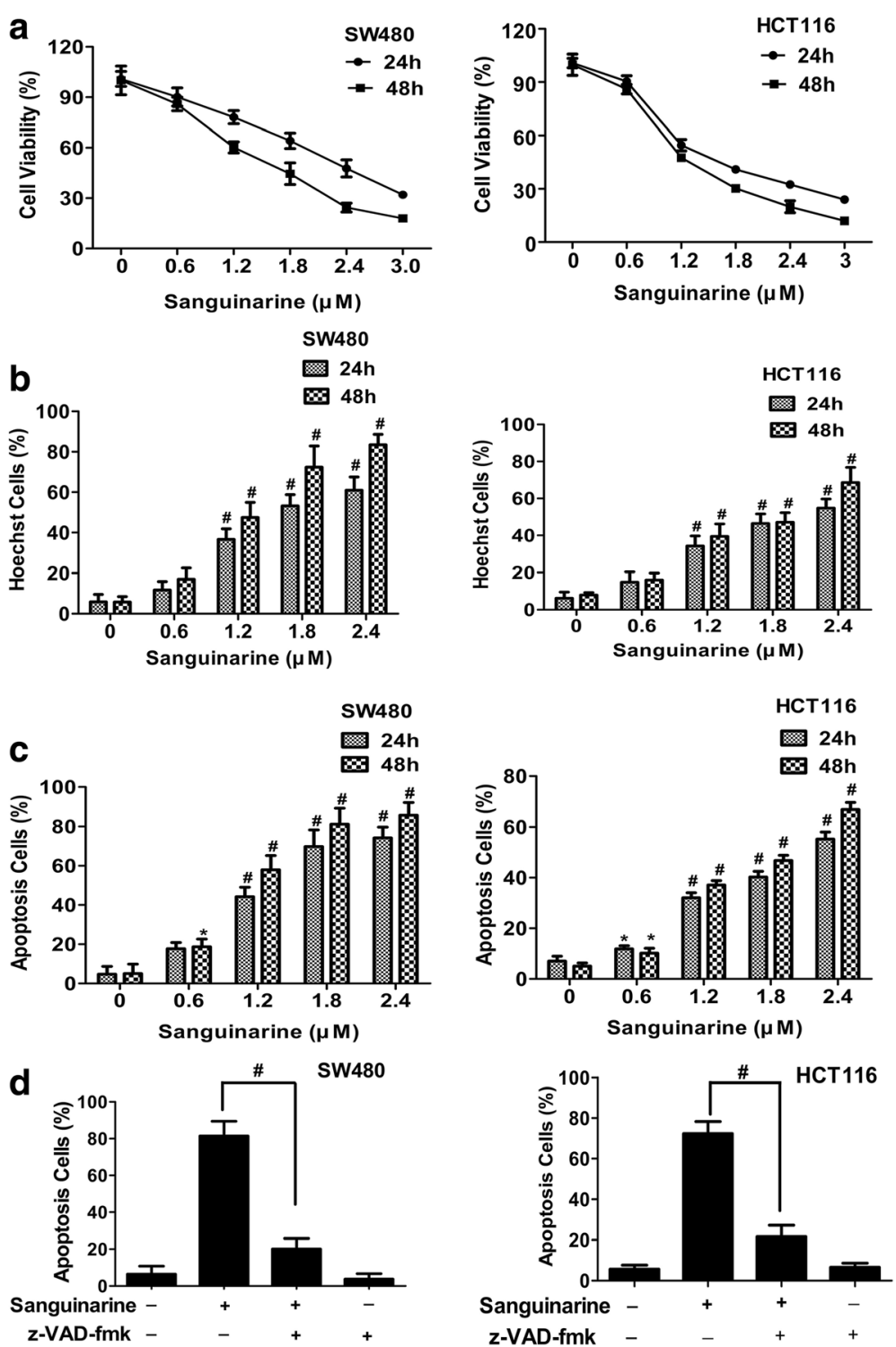

Fig. 2 Sanguinarine-induced apoptosis in CRC cells. a SW480 and HCT116 cells were treated with the indicated concentrations of sanguinarine for $24 \mathrm{~h}$ and $48 \mathrm{~h}$. Cell viability was measured by MTT assay $(n=5)$. b Cells were stained by DNA-specific Hoechst 33,342 dye. Hoechst positive cells were analyzed quantitatively by calculating the percentage of the number of cells with condensed chromatin $(n=3)$. c Cells were stained with PE-Annexin $V$ and 7-AAD and quantitatively analyzed by flow cytometry $(n=3)$. $\mathbf{d}$ Cells were pretreated with or without pan-caspase inhibitor, z-VAD-fmk $(50 \mu \mathrm{M})$ respectively, for $1 \mathrm{~h}$ before explosure to sanguinarine for $48 \mathrm{~h}$. Apoptosis cells were evaluated as described in $(\mathbf{c})(n=3)$. Data presented are showed as means \pm SD from three independent experiments. ${ }^{*} p<0.05$ and ${ }^{\#} p<0.01$ indicate significant difference

Bak to control the formation of the mitochondrial apoptosisinduced channel (MAC) [26]. Sanguinarine induced the activation of Bax and downregulated the expression of Bcl-2 (Fig. 3a). The activation of Bax was accompanied by the release of cytochrome $c$ from mitochondria to cytoplasm (Fig. 3b). The translocation of cytochrome $c$ suggested the opening of MAC and mitochondrial outer membrane permeabilization (MOMP). DCFH-DA staining further showed that the ROS was significantly elevated by sanguirnarine, which can be effectively suppressed by $\mathrm{L}-\mathrm{N}$-acetylcysteine treatment (Fig. 3c and d).
JC-1 staining showed that the mitochondrial membrane potential (MMP) was significantly reduced by sanguinarine in SW480 cells (Fig. 3e and Additional file 5: Figure S5). In the cytosol, cytochrome $c$ binds to Apaf- 1 , thereby triggering hierarchical activation of caspase- 9 and caspase- 3 [27]. The cleavage of caspase- 9 and caspase3 , and subsequent cleavage of PARP were observed in SW480 cells treated with sanguinarine (Fig. 3f). The cell viability was restored by NAC pretreatment and the cleavage of caspase- 3 and PARP was downregulated accordingly in cells treated with sanguinarine (Fig. $3 g$ and h). Taken 
a

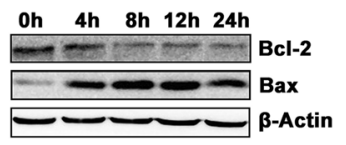

C

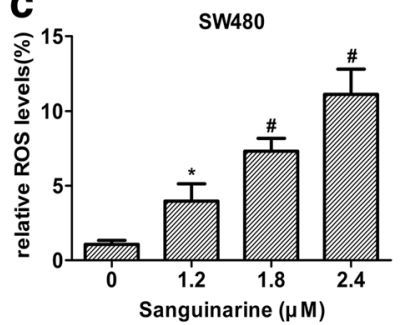

e
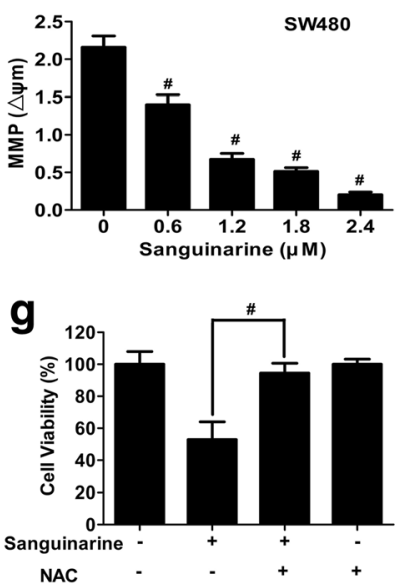

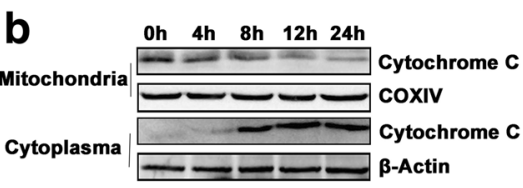

d

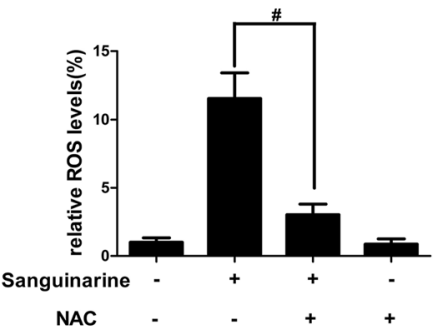

f

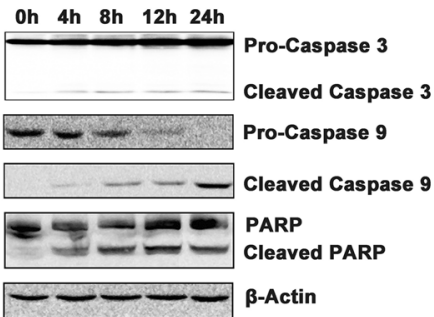

h

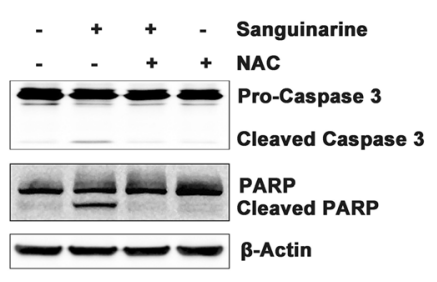

Fig. 3 Sanguinarine-induced apoptosis of CRC cells is an intrinsic apoptosis. a The expression of proteins from SW480 cells treated with $2.4 \mu M$ sanguinarine of $\mathrm{BCl}-2$ and Bax were determined by Western blotting. $\mathbf{b}$ Change of cytochrome $\mathrm{c}$ in mitochondrial and cytoplasmic fractions was analyzed by western blotting. COXIV and $\beta$-Actin were used to confirm equal protein loading respectively. $\mathbf{c}$ Cells were treated with the indicated concentrations of sanguinarine. ROS levels were evaluated by flow cytometry. $\mathbf{d}$ Cells were treated with or without $2.4 \mu \mathrm{M}$ sanguinarine for $12 \mathrm{~h}$ after pretreatment with or without $10 \mathrm{mM}$ NAC, a ROS scavenger, for $1 \mathrm{~h}$. ROS levels were evaluated by flow cytometry. e Mitochondria membrane potential $(\Delta \psi \mathrm{m})$ of SW480 cells was evaluated by JC-1 ratio of red and green fluorescence after sanguinarine treatment for $48 \mathrm{~h}$. $\mathbf{f}$ Whole cell lysates were subject to western-blotting analysis using an antibody against caspase-3, caspase-9, cleaved caspase-9 and PARP antibodies. $\mathbf{g}$ Cell viability was measured by MTT assay $(n=5)$. $\mathbf{h}$ Expression of the apoptosis proteins from SW480 cells treated with or without $2.4 \mu M$ sanguinarine after pretreatment with or without $10 \mathrm{mM} \mathrm{NAC}$ for $1 \mathrm{~h}$. Data presented are showed as means \pm SD from three independent experiments. ${ }^{*} p<0.05$ and ${ }^{\#} p<0.01$ indicate significant difference

together, these results suggested that sanguinarine induces intrinsic apoptosis by triggering MOMP [24, 28].

\section{Sanguinarine induces intrinsic apoptosis in a Bax- dependent manner}

To determine if the sanguinarine induced apoptosis is Baxdependent, HCT116 $\mathrm{Bax}^{+/+}$(wild type) and HCT116 $\mathrm{Bax}^{-/-}$ cells were adopted [24]. Our results showed that the reduced cell viability by sanguinarine was significantly antagonized in HCT116 $\mathrm{Bax}^{-/-}$cells (Fig. 4a). Correspondingly, sanguinarine-induced apoptosis was significantly lowered in HCT116 $\mathrm{Bax}^{-/}$cells (Fig. 4b). The apoptosis induced by sanguinarine in HCT116 $\mathrm{Bax}^{-/}$cells was partly rescued by Bax transfection. But it wasn't rescued by transfection of Bak (Additional file 6: Figure S6). The activation of $\mathrm{Bax}$ and downregulation of $\mathrm{Bcl}-2$ were both abolished in HCT116 $\mathrm{Bax}^{-/-}$cells (Fig. 4c). JC-1 staining further confirmed that for HCT116 (WT), the mitochondrial membrane potential decreased more significantly than that of HCT116 $\mathrm{Bax}^{-/}$(Additional file 7: Figure S7). Accordingly, the release of cytochrome $c$ from mitochondria (Fig. 4d) and the cleavage of caspase-9, and casapase- 3 were near totally abrogated in HCT116 $\mathrm{Bax}^{-/}$cells (Fig. 4e), either. These results provided consolidate evidence that Bax is a key regulator in sanguinarine-induced apoptosis [29].

Sanguinarine reduces the expression of STRAP and MELK STRAP is up-regulated in $60 \%$ colon carcinomas and demonstrates oncogenic function in multiple tumors 

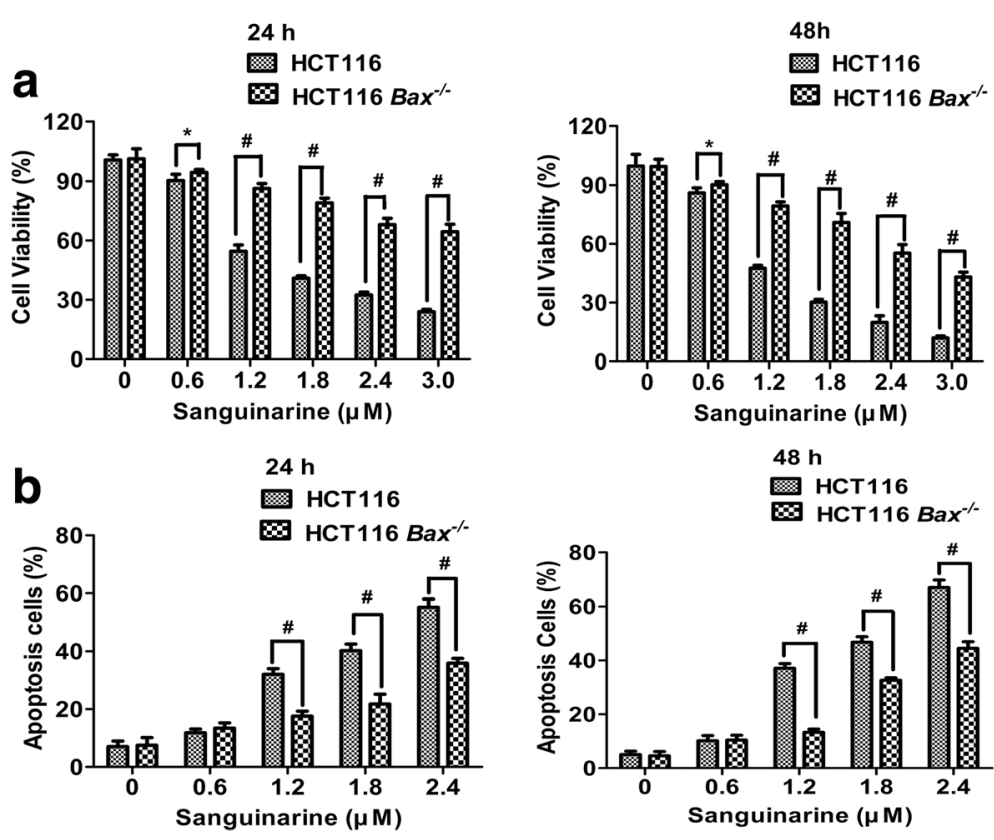

$48 \mathrm{~h}$

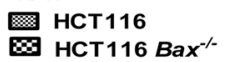

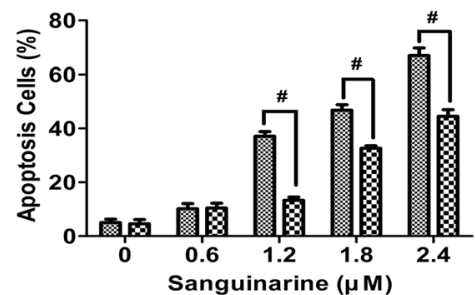

C

HCT116

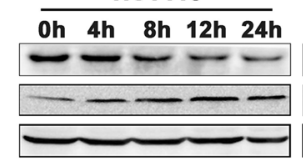

HCT116 Bax'-
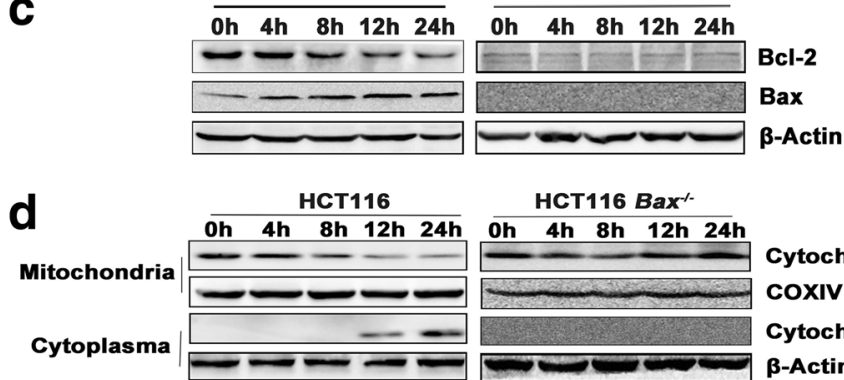

HCT116 Bax'

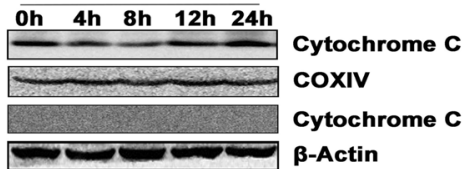

e

HCT116

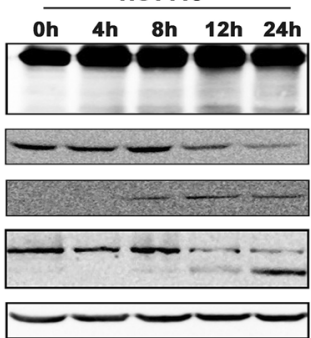

HCT116 Bax $^{\prime}$

Oh 4h 8h 12h 24h

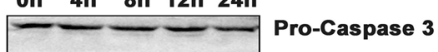

Cleaved Caspase 3

Pro-Caspase 9

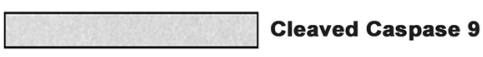

PARP

Cleaved PARP

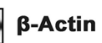

Fig. 4 Sanguinarine-induced apoptosis of CRC cells was Bax-depedent. a HCT116 WT and HCT116 Bax ${ }^{-/-}$cells were incubated with various concentrations of sanguinarine for $24 \mathrm{~h}$ and $48 \mathrm{~h}$. Cell viability was detected by MTT assay $(n=5)$. b Apoptosis cells were quantifiedby flow cytometry after PE-Annexin $\mathrm{V}$ and 7-AAD staining $(n=3)$. c Whole lysates were subjected to western blotting for expression of proteins of Bcl-2 and Bax. $\mathbf{d}$ Immunoblot was performed to evaluate cytochrome $\mathrm{C}$ in mitochondrial and cytoplasmic fractions. COXIV and $\beta$-Actin were served as loading control respectively. e The apoptosis regulatory proteins of whole lysates were analyzed by western blotting. Data presented are showed as means \pm SD from three independent experiments. ${ }^{*} p<0.05$ and ${ }^{\#} p<0.01$ indicate significant difference

[11]. qRT-PCR (Fig. 5a) and western blot (Fig. 5b) were used to observe the effects of sanguinarine on the expression of STRAP. These results showed that sanguinarine significantly reduced its expression.

It has been previously reported that STRAP was a medium of bonding between maternal embryonic leucine zipper kinase (MELK) and TGF- $\beta$ to regulate cell proliferation and apoptosis [9]. Interestingly, sanguinarine also decreased the expression of MELK in a timedependent manner (Fig. 5b). Furthermore, the phosphorylation of STRAP and MELK was downregulated in a dose dependent manner by sanguinarine treatment (Fig. 5b). In vitro kinase assay showed that the kinase activity of MELK was significantly downregulated by sanguinarine in a dose-dependent manner (Fig. 5c). Our experiments showed that interaction 


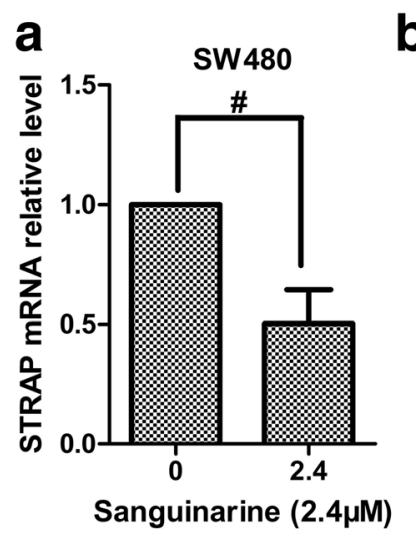

b
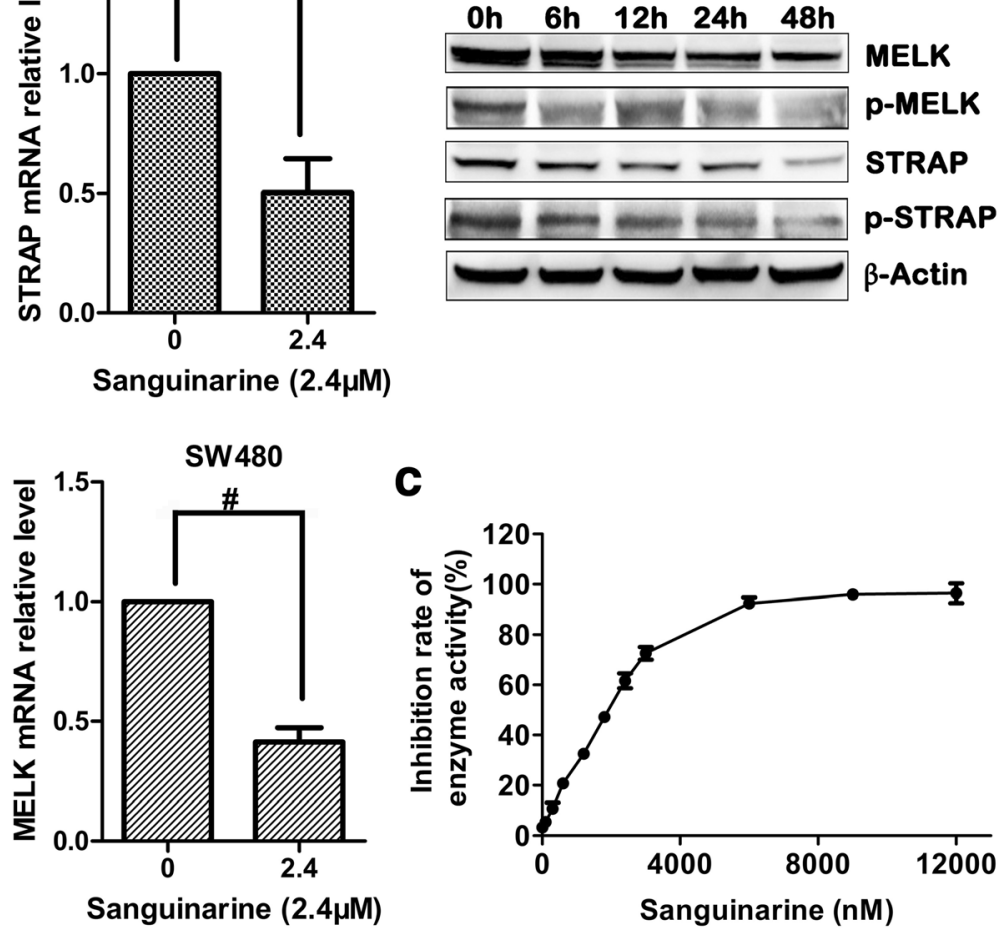

C

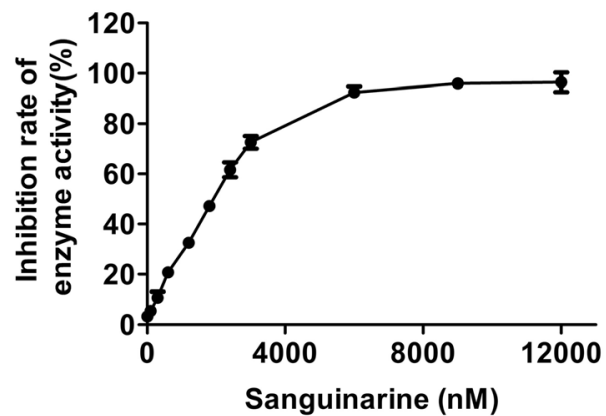

d

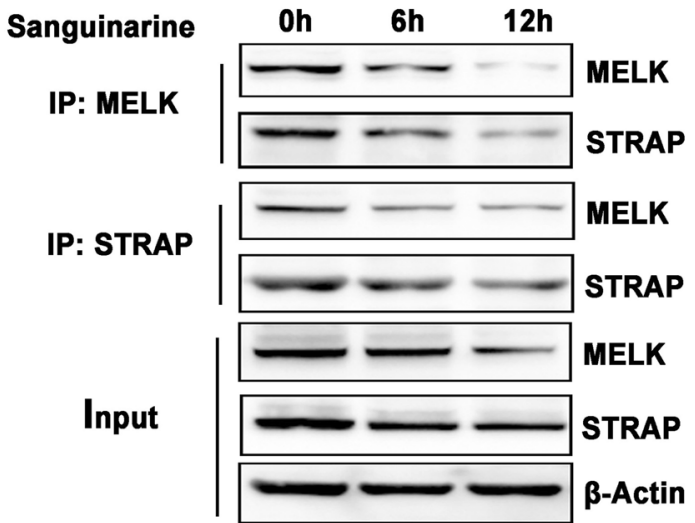

Fig. 5 Sanguinarine induced apoptosis of CRC cells by inhibition of the interaction of MELK and STRAP. a SW480 cells were treated with sanguinarine for $12 \mathrm{~h}$. STRAP and MELK mRNA relative level was detected by qRT-PCR. $\mathbf{b}$ Western blotting analysis of MELK, STRAP, p-MELK and p-STRAP in SW480 cells after treatment of $2.4 \mu \mathrm{M}$ sanguinarine for specified times. $\mathbf{c}$ The in vitro kinase activity of MELK was analyzed by using HTRF KinEASETM - STK kit. d The interaction between MELK and STRAP was analyzed by Co-IP. Cells were lysed and immunoprecipitated using an anti-MELK or STRAP antibody. The precipitated proteins were analyzed using westernblotting. Data presented are showed as means \pm SD from three independent experiments. ${ }^{*} p<0.01$ indicates significant difference

between STRAP and MELK was significantly disrupted in SW480 cells upon sanguinarine treatment (Fig. 5d). These data suggested that sanguinarine lowers the expression and phosphorylation of STRAP and MELK and disassociates the interaction between them.
Sanguinarine disassociates STRAP and MELK to induce Bax-dependent apoptosis

In breast cancer cells, MELK suppressed long isoform of Bcl-G (Bcl- $\left.\mathrm{G}_{\mathrm{L}}\right)$-induced apoptosis [30]. To verify the role of MELK in Bax-mediated apoptosis, its expressions in HCT116 and HCT116 $\mathrm{Bax}^{-/-}$cells treated with 
sanguinarine were documented. Contrary to the significantly reduced expression in sanguinarine treated HCT116, the expression of MELK and STRAP in HCT116 $\mathrm{Bax}^{-/-}$cells was slightly elevated (Fig. 6a and Additional file 8: Figure S8). Western blot provide further evidence that sanguinarine decreased the phosphorylation and expression of STRAP and MELK in HCT116 but increased their expression slightly in HCT116 $\mathrm{Bax}^{-/-}$cells at the same time (Fig. 6b). To test if the specific association between STRAP and MELK was regulated by Bax, we probed the immunocomplex using anti-STRAP and anti-MELK antibody to immunoprecipitate each other in HCT116 and HCT116 $\mathrm{Bax}^{-/-}$cells, respectively. As expected, the interaction between STRAP and MELK was weakened by sanguinarine in HCT116 but was enhanced in
HCT116 $\mathrm{Bax}^{-/-}$cells (Fig. 6c and d). Immunofluorescence confirmed the disassociation between STRAP and MELK in Bax positive cell treated with sanguinarine while showed strengthened association in HCT116 $\mathrm{Bax}^{-/-}$cells (Fig. 6e). These results suggested that the disrupted association between STRAP and MELK by sanguinarine was Baxdependent.

\section{Sanguinarine induces apoptosis in vivo through} downregulation and disassociation of STRAP and MELK The expression of Bax was elevated and the expressions of STRAP and MELK were decreased by sanguinarine treatment (Fig. 7a and b). When baited with MELK, immunoprecipitated STRAP were significantly reduced both in sanguinarine and cisplatin treated

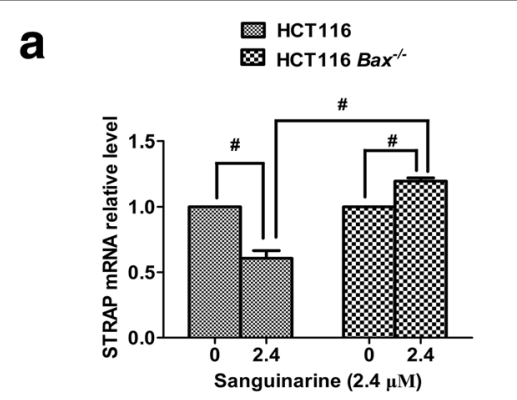

\section{b}
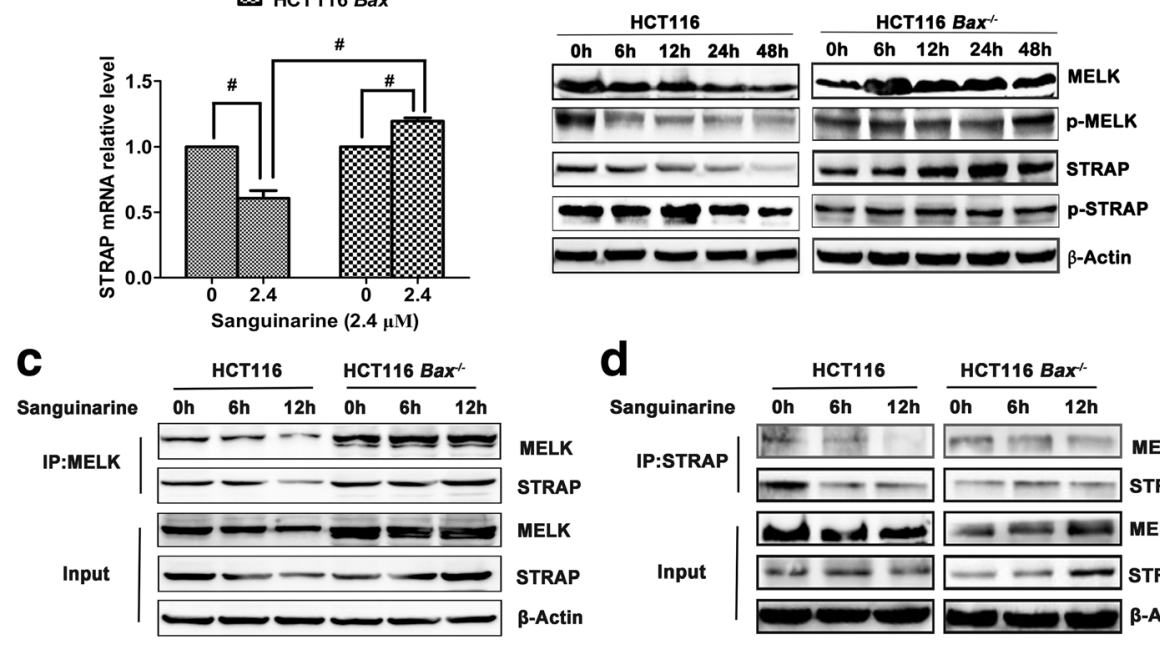

d

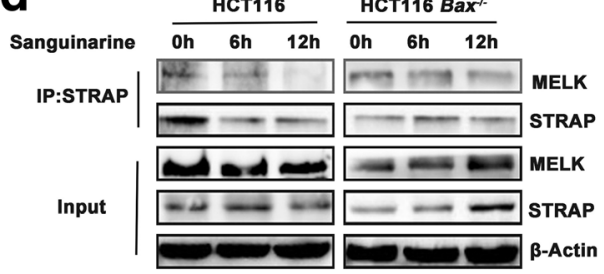

e

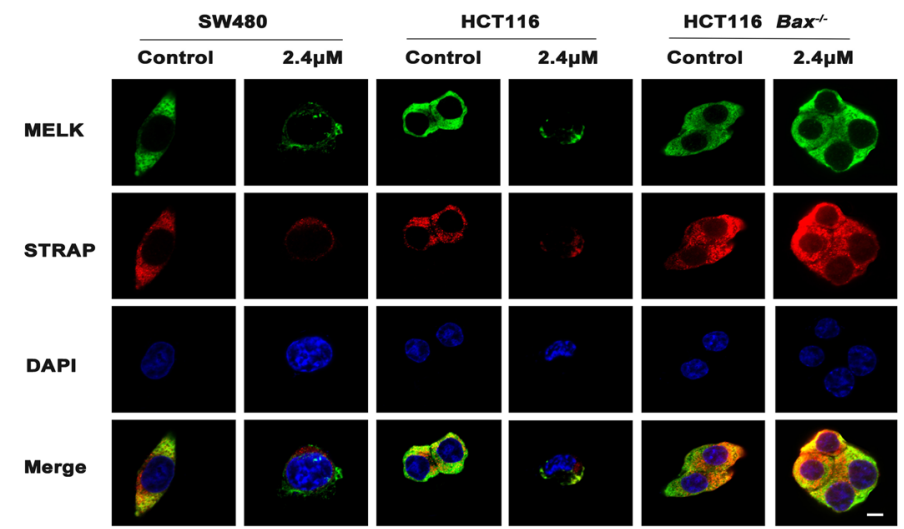

Fig. 6 Sanguinarine induces Bax-dependent disassociation between STRAP and MELK. a HCT116 WT and HCT116 Bax ${ }^{-/-}$cells were treated with sanguinarine for 12 h. RNA was extracted and qRT-PCR were performed to analyze STRAP mRNA relative level. $\mathbf{b}$ Protein expression of MELK, STRAP, p-MELK and p-STRAP was detected by western blotting. $\mathbf{c}$ and $\mathbf{d}$ The interaction between MELK and STRAP was analyzed by Co-IP. The lysate was subjected to immunoprecipitation with MELK (c) and STRAP (d) antibody respectively. Interaction of MELK and STRAP was evaluated by western blotting. e SW480, HCT116 WT and HCT116 $\mathrm{Bax}^{-/}$cells were treated respectivly with sanguinarine for $12 \mathrm{~h}$ and fixed by $4 \%$ paraformaldehyde. Cells were incubated with antibodies respectively and then probed secondary antibodies conjugated with FITC. Immunofluorescence imagines were observed under confocal microscopy (1000x) (Scale bar is $10 \mu \mathrm{m}$ ). Data presented are showed as means \pm SD from three independent experiments. \# $p<0.01$ indicates significant difference 


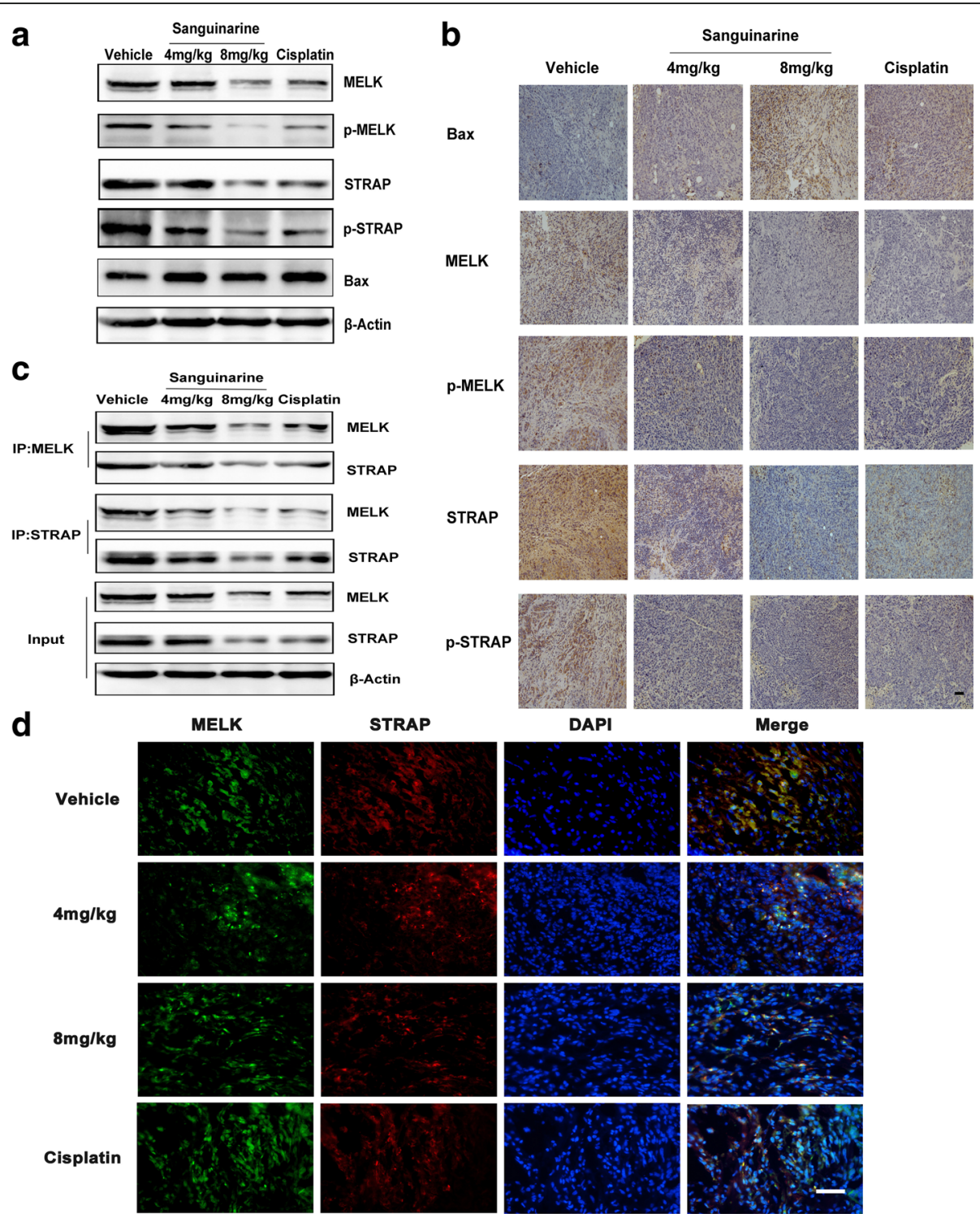

Fig. 7 Sanguinarine induces apoptosis in vivo through disassociation of STRAP and MELK. a The expression of MELK, p-MELK, STRAP and p-STRAP in tumor tissue was detected by western blotting analysis. b Representative images of immunohistochemical staining of Bax, MELK p-MELK, STRAP and p-STRAP in tumor tissues (200x) (Scale bar is 50 mm). c Primary antibodies of MELK and STRAP were added into the whole lysates from tumor tissue respectively. Co-IP MELK and STRAP was tested by western blotting. $\mathbf{d}$ Tumors from four groups were dissected, fixed and embedded using O.C.T gum. Interaction with STRAP and MELK was tested by double immune-fluorescence staining for MELK (green) and STRAP (red) in colon cancer tissues. Photoes were taken by inverted fluorescence microscope (400X) (Scale bar is $50 \mu \mathrm{m}$ )

tumor tissues extracts (Fig. 7c). When probed with STRAP, the attenuated interaction between STRAP and MELK was also observed. The interaction between MELK and STRAP was also suppressed by cisplatin (Fig. 7c). Immunofluorescence test showed that the association between MELK and STRAP was weakened significantly by sanguinarine (Fig. 7d). Collectively, our in vivo experiments again confirmed that sanguinarine decreases the growth of CRC through downregulation and disassociation of STRAP and MELK.
STRAP and MELK enhance oncogenic potential in colorectal specimens

To further explore the role of STRAP and MELK in tumorigenesis of CRC, the phosphorylation and expression of them were checked in CRC and paired normal tumor-adjacent colorectal tissues. No significant correlation was found between the expression level of MELK, STRAP and patients' age, gender, and tumor size. The expression and phosphorylation of MELK and STRAP were significantly elevated in CRC specimens as compared to the paired normal tissues (Fig. 8a and b). Both 
MELK and STRAP were significantly correlated with tumor stages. Furthermore, the expression of MELK, but not STRAP, was associated with lymph node metastasis (Table 1). These results suggested that both STRAP and MELK have oncogenic potential and might be promising molecular target for development of therapy for CRC patients.

\section{Discussion}

Our experimental data provide direct evidence that sanguinarine suppresses the growth of CRC through inducing intrinsic apoptosis in vivo. It induced Baxdependent apoptosis in multiple CRC cell lines both in dose- and time-dependent manner. It is consistent with the reports that sanguinarine promotes apoptosis in human CRC, bladder cancer, oral squamous cell carcinoma and primary effusion lymphoma cell lines, et al. [31-34]. However, these studies simply broached the subject of the effect of sanguinarine on Bax expression but did not define the underlying mechanisms. Our current study focused on these unaddressed mechanisms and found that MOMP is activated by sanguinarine and Bax is a key regulator in sanguinarine induced MOMP. Cytochrome $c$ is thus released from mitochondria into cytosol and subsequently triggers hierarchical activation of caspase-9, caspase-3 and caspase-7. Furthermore, we investigated that sanguinarine induced extrinsic apoptosis in CRC cells (Additional File 9: Figure S9).

Our results demonstrate that sanguinarine downregulates the expression of STRAP and MELK. Increased
Table 1 Correlation analysis of MELK, STRAP expression and clinical features

\begin{tabular}{|c|c|c|c|c|c|c|c|}
\hline \multirow[t]{2}{*}{ Characteristics } & \multirow{2}{*}{$\begin{array}{l}\text { Patients } \\
n=51\end{array}$} & \multicolumn{3}{|c|}{ MELK expression } & \multicolumn{3}{|c|}{ STRAP expression } \\
\hline & & low & high & $P$ value & low & high & $P$ value \\
\hline Gender & & & & 0.972 & & & 0.945 \\
\hline Male & 33 & 13 & 20 & & 15 & 18 & \\
\hline Female & 18 & 7 & 11 & & 8 & 10 & \\
\hline Age (year) & & & & 0.389 & & & 0.741 \\
\hline$\geq 60$ & 32 & 14 & 18 & & 15 & 17 & \\
\hline$<60$ & 19 & 6 & 13 & & 8 & 11 & \\
\hline Tumor size & & & & 0.431 & & & 0.461 \\
\hline$\geq 5 \mathrm{~cm}$ & 16 & 5 & 11 & & 6 & 10 & \\
\hline$<5 \mathrm{~cm}$ & 35 & 15 & 20 & & 17 & 18 & \\
\hline Tumor differention & & & & 0.544 & & & 0.931 \\
\hline Good & 0 & & & & & & \\
\hline Moderate & 47 & 19 & 28 & & 21 & 26 & \\
\hline Poor & 4 & 1 & 3 & & 2 & 2 & \\
\hline T-stage & & & & 0.026 & & & 0.013 \\
\hline $1-2$ & 10 & 7 & 3 & & 8 & 2 & \\
\hline $3-4$ & 41 & 13 & 28 & & 15 & 26 & \\
\hline $\mathrm{N}$-stage & & & & 0.024 & & & 0.991 \\
\hline 0 & 31 & 16 & 15 & & 14 & 17 & \\
\hline $1-2$ & 20 & 4 & 16 & & 9 & 11 & \\
\hline M-stage & & & & 0.832 & & & 0.491 \\
\hline 0 & 44 & 17 & 27 & & 19 & 25 & \\
\hline 1 & 7 & 3 & 4 & & 4 & 3 & \\
\hline
\end{tabular}
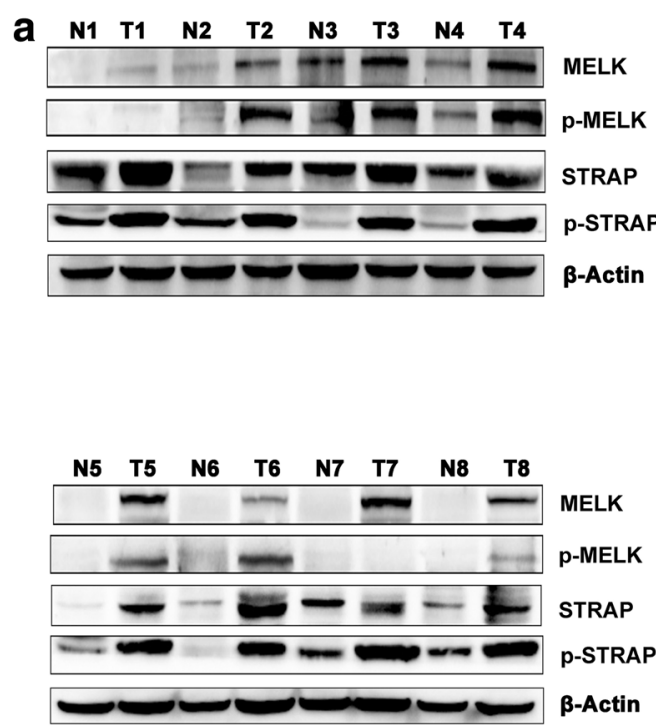

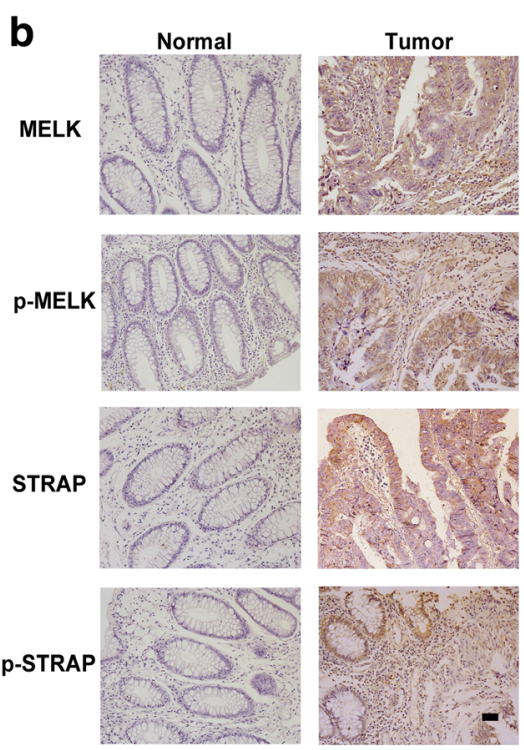

Fig. 8 Elevated MELK, p-MELK, STRAP and p-STRAP expression in colorectal cancer. a Western blotting analysis of MELK, p-MELK, STRAP and p-STRAP in CRC tissues (T) and the patient-matched adjacent non-tumor tissues ( $N$ ) was performed. $\beta$-Actin were used to confirm equal protein loading respectively. $\mathbf{b}$ Representative images of immunohistochemical staining of MELK, P-MELK, STRAP and p-STRAP in CRC tissues (T) and the patient-matched adjacent non-tumor tissues (N) (200x)(scale bar is $50 \mu \mathrm{m})$ 
MELK expression has been identified in multiple human cancers: prostate [14], breast [13], brain [35, 36], colorectal [37], gastric [38] and lung cancer [15]. The high expression of MELK is correlated aggressive subtypes and poor prognosis of breast cancer [13] and poorly differentiated phenotypes in human astrocytoma [35] and prostate cancers [14]. Upregulation of MELK drives cell cycle progression and tumor formation and it has been shown to be differentially expressed in cancer stem cells or tumor-initiating cells [39]. Its expression localizes to colorectal carcinoma and in particular the basal regions of crypts of normal gastrointestinal epithelium where the location of stem cells in normal colonic tissue [37]. These data suggests that sanguinarine might suppress malignant transformation and proliferation of CRC through downregulating expression of MELK. It has been reported that MELK was associated with increased resistance of colorectal cancer cells against radiation and 5-FU [40], sanguinarine mightbe a candidate therapy for apoptosis resistant patients.

Serine-threonine kinase receptor-associated protein (STRAP) is a novel tryptophan-aspartate 40 (WD40) domain-containing protein [11]. It is an oncogenic protein that is up-regulated in $60 \%$ of colorectal cancers and $78 \%$ of lung cancers and increases proliferate potential of tumor cells $[10,11]$. STRAP acts as a negative regulator of apoptosis signal-regulating kinase 1 and suppresses apoptosis in a dose-dependent manner [41]. It is consistent with our results that sanguinarine downregulates STRAP and induces apoptosis in CRC cell lines.

The orthotopical models showed the efficacy of sanguinarine with less body weight loss, suggested its translational potential as an anti-CRC agent with less toxicity. Sanguinarine downregulates the expression of MELK and STRAP in CRC tissues. Furthermore, it attenuates the association between MELK and STRAP. Sanguinarine induces intrinsic apoptosis in the presence of Bax. The weakened interaction of MELK and STRAP is necessary for the transactivation of Bax from cytosol to mitochondria. The accumulation of Bax in the mitochondria induces MOMP which cause the release of cytochrome $c$ into the cytosol from mitochondria [24].

STRAP and MELK are highly expressed and phosphorylated in tissues of CRC patients. The strengthened association between them might be a marker for the formation of CRC. The attenuated formation of MELK and STRAP complex can be observed in cells treated with sanguinarine, and can also be induced by sanguinarine in mice bearing CRC tumors. These data provide evidence that sanguinarine induces intrinsic apoptosis through downregulation and disassociation of MELK and STRAP. MELK and STRAP are potential therapeutic targets that for triggering MOMP in CRC.

\section{Conclusions}

STRAP and MELK are potential pro-tumoral markers of CRC. Sanguinarine shows efficacious anti-tumor effects through downregulating and dephosphorelating STRAP and MELK. Sanguinarine disassociates the interaction between STRAP and MELK to trigger intrinsic apoptosis.

\section{Additional files}

\begin{abstract}
Additional file 1: Figure S1. Apoptosis was detected in SW480 cells treated with sanguinarine. Cells were treated with the indicated concentrations of sanguinarine for $24 \mathrm{~h}$ and $48 \mathrm{~h}$ and then stained by DNA-specific Hoechst 33,342 dye. Imagines were observed by inverted fluorescence microscope (400x). Scale bar is $50 \mu \mathrm{m}$. (TIF $16868 \mathrm{~kb}$ )
\end{abstract}

Additional file 2: Figure S2. Apoptosis was detected in HCT116 cells treated with sanguinarine. Cells were treated with the indicated concentrations of sanguinarine for $24 \mathrm{~h}$ and $48 \mathrm{~h}$ and then stained by DNA-specific Hoechst 33,342 dye. Imagines were observed by inverted fluorescence microscope (400x). Scale bar is $50 \mu \mathrm{m}$. (TIF $16794 \mathrm{~kb}$ )

Additional file 3: Figure S3. Apoptotic cells were significantly increased by sanguinarine treatment. Indicated CRC cell lines were treated with the various concentrations of sanguinarine. To detect the degree of apoptosis, cells were analyzed by flow cytometry after PE-Annexin $V$ and 7-AAD staining. (TIF $15845 \mathrm{~kb}$ )

Additional file 4: Figure S4. Z-VAD-fmk inhibited sanguinarine-induced apoptosis in CRC cells. After treatment with the combination of sanguinarine and Z-VAD-fmk (50 $\mu \mathrm{M})$, cells were analyzed using flow cytometry. (TIF 5542 kb)

Additional file 5: Figure S5. Change of the mitochondrial membrane potential (MMP) in SW480 cells by sanguinarine. Cells were treated with the various concentrations of sanguinarine and stained with JC-1. Mean JC-1 fluorescence intensity was evalued by a flow cytometer. (TIF $2721 \mathrm{~kb}$ )

Additional file 6: Figure S6. Detection of Apoptosis in Bax-overexpressing or BAK-overexpressing $\mathrm{HCT} 116 \mathrm{Bax}^{-/-}$cells treated with sanguinarine. $\mathbf{a}$ and $\mathbf{b}$ HCT116 $\mathrm{Bax}^{-1-}$ cells were transfected with pcDNA3.1-Bax (a) or pcDNA3.1-BAK (b) and examined by western blotting for the expression of the proteins. $\mathbf{C}$ After HCT1 16 or Bax-overexpressing or BAK-overexpressing HCT116 Bax ${ }^{-1}$ cells treated with sanguinarine for $24 \mathrm{~h}$, apoptosis was detected. (TIF $1013 \mathrm{~kb}$ )

Additional file 7: Figure S7. Comparison of the mitochondrial membrane potential in HCT116 WT and HCT116 $\mathrm{Bax}^{-/-}$treated with sanguinarine. Cells were treated with the various concentrations of Sanguinarine and stained with JC-1. Mean JC-1 fluorescence intensity was evalued by a flow cytometer. (TIF $6622 \mathrm{~kb}$ )

Additional file 8: Figure S8. HCT116 WT and HCT116 $\mathrm{Bax}^{-/-}$cells were treated with sanguinarine for $12 \mathrm{~h}$. RNA was extracted and qRT-PCR were performed to analyze MELK mRNA relative level. ${ }^{\#} p<0.01$ indicates significant difference. (TIF $2220 \mathrm{~kb}$ )

Additional file 9: Figure S9. SW480 cells were treated with sanguinarine for indicated time. The experession of Caspase 8 protein was examined using western blotting. (TIF $614 \mathrm{~kb}$ )

\section{Abbreviations}

CRC: Colorectal cancer; MELK: Maternal embryonic leucine zipper kinase; MOMP: Mitochondrial outer membrane permeabilization; STRAP: Serinethreonine kinase receptor-associated protein

\section{Acknowledgements}

We thank Dr. Bert Vogelstein of Howard Hughes Medical Institute for HCT116 Bax $^{-/-}$cell lines.

\section{Funding}

The work was supported by National Natural Science Foundation of China (Grant No. 81774172 and 81573848), Guangdong Natural Science Foundation (Grant No. 2014A030313323), Planned Science Technology Project of Guangzhou (Grant No. 201607010146). There was no role of the funding 
bodies in the design of the study and collection, analysis, and interpretation of data and in writing the manuscript.

\section{Availability of data and materials}

Majority of datasets generated or analyzed during the study are included in this published article. Remaining raw data used during the current study are available from the corresponding author on reasonable request.

\section{Authors contributions}

The experiments were conceived and planned by XS, XY and XG. XS drafted and critically revised the manuscript and was responsible for management of the project. XG carried out experiments and data analysis and prepared the manuscript. ZC and $\mathrm{OH}$ performed experiments, data statistics and submission. CC participated in animal experiments. $L, Y L, L Z$ and $X Y$ participated in the discussion and data interpretation. All authors have read and approved the final version of the manuscript.

\section{Ethics approval and consent to participate}

The studies involving patient materials were in agreement with written informed consent for participation and approved by the Ethics Committee of Guangdong General Hospital. The use and care of experimental animals were approved by the Laboratory Animals Care and Use Committee of Southern Medical University, China.

\section{Competing interests}

The authors declare no potential conflicts of interest.

\section{Publisher's Note}

Springer Nature remains neutral with regard to jurisdictional claims in published maps and institutional affiliations.

\section{Author details}

${ }^{1}$ The key laboratory of molecular biology, State Administration of Traditional Chinese Medicine, School of Traditional Chinese Medicine, Southern Medical University, Guangdong, Guangzhou (510515), China. ${ }^{2}$ School of pharmacy, Guangdong Medical University, Guangdong, Dongguan (523808), China.

${ }^{3}$ Traditional Chinese Medicine Integrated Hospital, Southern Medical University, Guangdong, Guangzhou (510315), China. ${ }^{4}$ Nanfang hospital, Southern Medical University, Guangzhou (510515), China. ${ }^{5}$ Department of Gastrointestinal Surgery, Guangdong General Hospital, Guangzhou (510120), China.

Received: 26 October 2017 Accepted: 30 April 2018 Published online: 21 May 2018

\section{References}

1. Siegel RL, Miller KD, Jemal A. Cancer statistics, 2017. CA Cancer J Clin. 2017; 67(1):7-30.

2. Siegel R, Ward E, Brawley O, Jemal A. Cancer statistics, 2011: the impact of eliminating socioeconomic and racial disparities on premature cancer deaths. CA Cancer J Clin. 2011:61(4):212-36.

3. Jendrossek $\mathrm{V}$. The intrinsic apoptosis pathways as a target in anticancer therapy. Curr Pharm Biotechnol. 2012;13(8):1426-38.

4. Ren D, Tu HC, Kim H, Wang GX, Bean GR, Takeuchi O, Jeffers JR, Zambetti GP, Hsieh JJ, Cheng EH. BID, BIM, and PUMA are essential for activation of the BAX- and BAK-dependent cell death program. Science. 2010;330(6009):1390-3.

5. Yee C, Yang W, Hekimi S. The intrinsic apoptosis pathway mediates the pro-longevity response to mitochondrial ROS in C. Elegans. Cell. 2014;157(4): 897-909.

6. Abraha AM, Ketema EB. Apoptotic pathways as a therapeutic target for colorectal cancer treatment. World J Gastrointest Oncol. 2016;8(8):583-91.

7. Hector $\mathrm{S}$, Prehn $\mathrm{JH}$. Apoptosis signaling proteins as prognostic biomarkers in colorectal cancer: a review. Biochim Biophys Acta. 2009;1795(2):117-29.

8. Huerta S, Goulet EJ, Livingston EH. Colon cancer and apoptosis. Am J Surg. 2006;191(4):517-26.

9. Seong HA, Manoharan R, Ha H. A crucial role for the phosphorylation of STRAP at Ser(188) by MPK38 in STRAP-dependent cell death through ASK1, TGF-beta, p53, and PI3K/PDK1 signaling pathways. Cell Cycle. 2014;13(21): $3357-74$.
10. Manoharan R, Seong HA, Ha H. Thioredoxin inhibits MPK38-induced ASK1 TGF-beta, and p53 function in a phosphorylation-dependent manner. Free Radic Biol Med. 2013;63:313-24.

11. Halder SK, Anumanthan G, Maddula R, Mann J, Chytil A, Gonzalez AL Washington MK, Moses HL, Beauchamp RD, Datta PK. Oncogenic function of a novel WD-domain protein, STRAP, in human carcinogenesis. Cancer Res. 2006;66(12):6156-66.

12. Kim CJ, Choi BJ, Song JH, Park YK, Cho YG, Nam SW, Yoo NJ, Lee JY, Park WS. Overexpression of serine-threonine receptor kinase-associated protein in colorectal cancers. Pathol Int. 2007;57(4):178-82.

13. Pickard MR, Green AR, Ellis IO, Caldas C, Hedge VL, Mourtada-Maarabouni M, Williams GT. Dysregulated expression of Fau and MELK is associated with poor prognosis in breast cancer. Breast Cancer Res. 2009;11(4):R60.

14. Kuner R, Falth M, Pressinotti NC, Brase JC, Puig SB, Metzger J, Gade S, Schafer G, Bartsch G, Steiner E, et al. The maternal embryonic leucine zipper kinase (MELK) is upregulated in high-grade prostate cancer. J Mol Med (Berl). 2013:91(2):237-48

15. Inoue H, Kato T, Olugbile S, Tamura K, Chung S, Miyamoto T, Matsuo Y, Salgia R, Nakamura Y, Park JH. Effective growth-suppressive activity of maternal embryonic leucine-zipper kinase (MELK) inhibitor against small cell lung cancer. Oncotarget. 2016;7(12):13621-33.

16. Liu M, Lin YL, Chen XR, Liao CC, Poo WK. In vitro assessment of Macleaya cordata crude extract bioactivity and anticancer properties in normal and cancerous human lung cells. Exp Toxicol Pathol. 2013;65(6):775-87.

17. Wang $Y$, Zhang B, Liu W, Dai Y, Shi Y, Zeng Q, Wang F. Noninvasive bioluminescence imaging of the dynamics of sanguinarine induced apoptosis via activation of reactive oxygen species. Oncotarget. 2016; 7(16):22355-67.

18. Han MH, Kim GY, Yoo YH, Choi YH. Sanguinarine induces apoptosis in human colorectal cancer HCT-116 cells through ROS-mediated Egr-1 activation and mitochondrial dysfunction. Toxicol Lett. 2013;220(2):157-66.

19. Gatti L, Cossa G, Tinelli S, Carenini N, Arrighetti N, Pennati M, Cominetti D, De Cesare M, Zunino F, Zaffaroni N, et al. Improved apoptotic cell death in drug-resistant non-small-cell lung cancer cells by tumor necrosis factorrelated apoptosis-inducing ligand-based treatment. J Pharmacol Exp Ther. 2014;348(3):360-71.

20. Luna-Vargas MP, Chipuk JE. Physiological and pharmacological control of BAK, BAX, and beyond. Trends Cell Biol. 2016;26(12):906-17.

21. Zeng P, Liu B, Wang Q, Fan Q, Diao JX, Tang J, Fu XQ, Sun XG. Apigenin attenuates Atherogenesis through inducing macrophage apoptosis via inhibition of AKT Ser473 phosphorylation and downregulation of plasminogen activator Inhibitor-2. Oxidative Med Cell Longev. 2015;2015:379538.

22. Yang Y, Su Y, Wang D, Chen Y, Wu T, Li G, Sun X, Cui L. Tanshinol attenuates the deleterious effects of oxidative stress on osteoblastic differentiation via Wnt/FoxO3a signaling. Oxidative Med Cell Longev. 2013;2013:351895.

23. Chunhua L, Donglan L, Xiugiong F, Lihua Z, Qin F, Yawei L, Liang Z, Ge W Linlin J, Ping Z, Kun L, Xuegang S. Apigenin up-regulates transgelin and inhibits invasion and migration of colorectal cancer through decreased phosphorylation of AKT. J Nutr Biochem. 2013;24(10):1766-75.

24. Xu W, Jing L, Wang Q, Lin CC, Chen X, Diao J, Liu Y, Sun X. Bax-PGAM5L-Drp complex is required for intrinsic apoptosis execution. Oncotarget. 2015;6(30): 30017-34

25. Zhao L, Wang H, Liu C, Liu Y, Wang X, Wang S, Sun X, Li J, Deng Y, Jiang Y, et al. Promotion of colorectal cancer growth and metastasis by the LIM and SH3 domain protein 1. Gut. 2010:59(9):1226-35.

26. Dejean LM, Martinez-Caballero S, Guo L, Hughes C, Teijido O, Ducret T, Ichas F, Korsmeyer SJ, Antonsson B, Jonas EA, et al. Oligomeric Bax is a component of the putative cytochrome $\mathrm{c}$ release channel MAC, mitochondrial apoptosis-induced channel. Mol Biol Cell. 2005;16(5):2424-32.

27. Slee EA, Harte MT, Kluck RM, Wolf BB, Casiano CA, Newmeyer DD, Wang HG, Reed JC, Nicholson DW, Alnemri ES, et al. Ordering the cytochrome c-initiated caspase cascade: hierarchical activation of caspases-2, $-3,-6,-7,-8$, and -10 in a caspase-9-dependent manner. J Cell Biol. 1999;144(2):281-92.

28. Galluzzi L, Vitale I, Abrams JM, Alnemri ES, Baehrecke EH, Blagosklonny MV, Dawson TM, Dawson VL, El-Deiry WS, Fulda S, et al. Molecular definitions of cell death subroutines: recommendations of the nomenclature committee on cell death 2012. Cell Death Differ. 2012;19(1):107-20.

29. Adhami VM, Aziz MH, Mukhtar $\mathrm{H}$, Ahmad $\mathrm{N}$. Activation of prodeath Bcl-2 family proteins and mitochondrial apoptosis pathway by sanguinarine in immortalized human $\mathrm{HaCaT}$ keratinocytes. Clin Cancer Res. 2003:9(8):3176-82. 
30. Lin ML, Park JH, Nishidate T, Nakamura Y, Katagiri T. Involvement of maternal embryonic leucine zipper kinase (MELK) in mammary carcinogenesis through interaction with BCl-G, a pro-apoptotic member of the BCl-2 family. Breast Cancer Res. 2007;9(1):R17.

31. Lee JS, Jung WK, Jeong MH, Yoon TR, Kim HK. Sanguinarine induces apoptosis of HT-29 human colon cancer cells via the regulation of $\mathrm{Bax} / \mathrm{BCl}-2$ ratio and caspase-9-dependent pathway. Int J Toxicol. 2012;31(1):70-7.

32. Han MH, Park C, Jin CY, Kim GY, Chang YC, Moon SK, Kim WJ, Choi YH. Apoptosis induction of human bladder cancer cells by sanguinarine through reactive oxygen species-mediated up-regulation of early growth response gene-1. PLoS One. 2013;8(5):e63425.

33. Tsukamoto $H$, Kondo S, Mukudai $Y$, Nagumo T, Yasuda A, Kurihara $Y$, Kamatani T, Shintani S. Evaluation of anticancer activities of benzo[c]phenanthridine alkaloid sanguinarine in oral squamous cell carcinoma cell line. Anticancer Res. 2011:31(9):2841-6.

34. Hussain AR, Al-Jomah NA, Siraj AK, Manogaran P, Al-Hussein K, Abubaker J, Platanias LC, Al-Kuraya KS, Uddin S. Sanguinarine-dependent induction of apoptosis in primary effusion lymphoma cells. Cancer Res. 2007;67(8):3888-97.

35. Marie SK, Okamoto OK, Uno M, Hasegawa AP, Oba-Shinjo SM, Cohen T, Camargo AA, Kosoy A, Carlotti CJ, Moreira-Filho CA TS, Zago MA, Simpson AJ, Caballero OL. Maternal embryonic leucine zipper kinase transcript abundance correlates with malignancy grade in human astrocytomas. Int J Cancer. 2008;122(4):807-15

36. Nakano I, Masterman-Smith M, Saigusa K, Paucar AA, Horvath S, Shoemaker L, Watanabe M, Negro A, Bajpai R, Howes A, et al. Maternal embryonic leucine zipper kinase is a key regulator of the proliferation of malignant brain tumors, including brain tumor stem cells. J Neurosci Res. 2008;86(1):48-60.

37. Gray D, Jubb AM, Hogue D, Dowd P, Kljavin N, Yi S, Bai W, Frantz G, Zhang Z, Koeppen H, et al. Maternal embryonic leucine zipper kinase/murine protein serine-threonine kinase 38 is a promising therapeutic target for multiple cancers. Cancer Res. 2005;65(21):9751-61.

38. Du T, Qu Y, Li J, Li H, Su L, Zhou Q, Yan M, Li C, Zhu Z, Liu B. Maternal embryonic leucine zipper kinase enhances gastric cancer progression via the FAK/Paxillin pathway. Mol Cancer. 2014;13:100.

39. Hebbard LW, Maurer J, Miller A, Lesperance J, Hassell J, Oshima RG, Terskikh AV. Maternal embryonic leucine zipper kinase is upregulated and required in mammary tumor-initiating cells in vivo. Cancer Res. 2010;70(21):8863-73.

40. Choi S, Ku JL. Resistance of colorectal cancer cells to radiation and 5-FU is associated with MELK expression. Biochem Biophys Res Commun. 2011; 412(2):207-13

41. Jung $H$, Seong $H A$, Manoharan $R, H a H$. Serine-threonine kinase receptorassociated protein inhibits apoptosis signal-regulating kinase 1 function through direct interaction. J Biol Chem. 2010;285(1):54-70.

\section{Ready to submit your research? Choose BMC and benefit from:}

- fast, convenient online submission

- thorough peer review by experienced researchers in your field

- rapid publication on acceptance

- support for research data, including large and complex data types

- gold Open Access which fosters wider collaboration and increased citations

- maximum visibility for your research: over $100 \mathrm{M}$ website views per year 